The Effect of Short-Term Vitamin D Supplementation on Calcium Status in Vitamin D Insufficient Renal Transplant Recipients at Risk of Hypercalcaemia.

Irene Lynch Cronin BSc ${ }^{1,2}$, Fiona Byrne MSc ${ }^{1,2}$, Ross Doyle MB, BAO, $\mathrm{BCh}^{2}$, William D Fraser MD FRCP FRCPath ${ }^{3,4}$, Allison Chipchase PhD FRCPath ${ }^{4}$, Joseph A Eustace FRCPI ${ }^{2,5}$

1 Department of Clinical Nutrition and Dietetics, Cork University Hospital, Cork, Ireland

2 Department of Renal Medicine, Cork University Hospital, Cork, Ireland

3 University of East Anglia, Department of Medicine, Norwich, UK

$4 \quad$ Norfolk and Norwich University Hospitals, Colney Lane, Norwich, UK

$5 \quad$ HRB Clinical Research Facility, Cork, Ireland

Corresponding author: Irene Lynch Cronin. Department of Clinical Nutrition and Dietetics. Cork University Hospital, Wilton, Cork. Ireland. Tel: 00353 214922169. Fax: 00353214920143

E-mail: Irene.Cronin@hse.ie

Abstract Word Count: 271

Manuscript Word Count: 3293

Short Title: Vitamin D and calcium post-transplant

Acknowledgements: The authors thank the renal clinical nurse specialists and phlebotomists of Cork University Hospital and the research nurses of the Clinical Research Facility for their assistance in collecting the blood samples. 
Financial Disclosure: This work was supported by the HRB Clinical Research Facility, Cork, Ireland and the vitamin D supplements were provided free of charge by Shield Health, Dublin, Ireland. 


\section{The Effect of Short-Term Vitamin D Supplementation on Calcium Status in Vitamin D Insufficient Renal Transplant Recipients at risk of Hypercalcaemia.}

Objective: Vitamin D insufficiency is highly prevalent amongst renal transplant recipients and in observational studies is associated with adverse outcomes. Hypercalcaemia, usually due to persistent hyperparathyroidism, also commonly occurs in this population and often coexists with vitamin D insufficiency. However, concern that vitamin D supplementation might exacerbate the pre-existing hypercalcaemia often leads clinicians to avoid vitamin D supplementation in such patients. This feasibility study aimed to quantify the effect on serum calcium of short-term lowdose cholecalciferol supplementation in a group of renal transplant recipients with a recent history of serum calcium levels $>10 \mathrm{mg} / \mathrm{dL}$.

Design: This was a two-week, single arm, open-label trial.

Setting: Renal transplant follow-up clinic in an Irish University Hospital.

Subjects: 18 vitamin D insufficient adult patients with a functioning renal allograft (eGFR $>30$ $\mathrm{ml} / \mathrm{min} / 1.73 \mathrm{~m}^{2}$ ) and a recent history of serum calcium $>10 \mathrm{mg} / \mathrm{dL}$.

Intervention: Two weeks of treatment with $1000 \mathrm{IU}$ cholecalciferol/day.

Main Outcome Measure: Change in plasma ionized calcium and urine calcium:creatinine ratio at follow-up as compared to baseline.

Results: The mean (sd) baseline $25(\mathrm{OH})$ vitamin D (25 (OH) D) concentration was 15.9 (5.97) $\mathrm{ng} / \mathrm{mL}$ and the mean (sd) baseline serum calcium was $10.50(0.6) \mathrm{mg} / \mathrm{dL}$. Following the 2-week intervention, median (IQR) change in serum calcium from baseline to follow-up was -0.08 (-3.6 to 0.08$) \mathrm{mg} / \mathrm{dL}, \mathrm{p}=0.3$. Mean ( $\mathrm{sd}$ ) ionized calcium decreased from $5.24(0.32) \mathrm{mg} / \mathrm{dL}$ at baseline 
to $5.16(0.28) \mathrm{mg} / \mathrm{dL}, \mathrm{p}=0.05$. The median (IQR) change in the urinary calcium:creatinine ratio was $0.001(-0.026$ to 0.299$) \mathrm{mg} / \mathrm{mg}, \mathrm{p}=0.88$. The median (IQR) change in $25(\mathrm{OH}) \mathrm{D}$ was $3.6(2.9$ to 6.2$) \mathrm{ng} / \mathrm{mL}, \mathrm{p}<0.05$.

Conclusions: In vitamin D insufficient renal transplant recipients at risk of hypercalcaemia, lowdose short-term oral cholecalciferol supplementation improves $25(\mathrm{OH}) \mathrm{D}$ concentrations without exacerbating hypercalcaemia or increasing the urinary calcium:creatinine ratio.

Keywords: Vitamin D, hypercalaemia, renal transplant 


\section{Introduction}

It is well established that there is a high prevalence of vitamin D insufficiency (up to 94\%) among renal transplant recipients. ${ }^{1,2}$ The reasons for this trend to insufficiency are several fold including recommendations to minimize sun exposure advising use of sunscreens with a high sun protection factor (SPF) due to increased risk of skin cancer among the renal transplant population, inadequate nutritional vitamin $\mathrm{D}$ supplementation both during dialysis and after transplantation, and an increased vitamin D catabolism due to immunosuppressive drugs. ${ }^{3}$ These are compounded by the same risk factors that affect the general healthy population which contribute to vitamin D insufficiency such as dietary inadequacy, obesity, aging, skin pigmentation, seasonality and latitude, as well as concomitant medications that affect vitamin $\mathrm{D}$ metabolism. ${ }^{4}$

Vitamin D receptors are found in an array of tissues and organs in the body including the intestine and bone, the brain, heart, skin, breast and other organs where vitamin D has an important role in muscle function, immunity, cellular growth and maturation in addition to its classical role in bone metabolism. It is now recognised that many extra-renal cell types express one-alpha hydroxylase with intracellular conversion of $25(\mathrm{OH}) \mathrm{D}$ to $1,25(\mathrm{OH})_{2} \mathrm{D}$ which exerts its effects at cellular level, including cell proliferation, induction of apoptosis and cell differentiation in an autocrine/paracrine function. ${ }^{5}$ Increasingly, epidemiological studies are reporting an association between low $25(\mathrm{OH}) \mathrm{D}$ status and various diseases including cancer of the breast, ovaries and colon as well as cardiovascular and infectious disease. ${ }^{6}$

While the effect of improved vitamin D status on bone disease and other conditions in renal transplant recipients has not been established in large randomised studies, based on 
epidemiological studies of bone health it appears prudent to avoid deficiency. Vitamin D status is also associated with a range of renal transplant outcomes. A recent observational study of 435 stable long-term renal transplant recipients demonstrated that low $25(\mathrm{OH}) \mathrm{D}$ is independently associated with a higher risk of all-cause mortality, with deficiency $(<12 \mathrm{ng} / \mathrm{mL})$ being independently and significantly associated with a faster annual decrease in renal function. ${ }^{7}$ Filipov et $\mathrm{al}^{8}$ in a retrospective observational study showed that higher vitamin D status is associated with lower proteinuria in kidney transplant recipients.

A concern regarding the use of vitamin D supplementation is the potential increase in enteric calcium and phosphate absorption. This is a particular concern as a substantial minority of renal transplants are mildly hypercalcaemic. There is a dearth of research examining the use of nutritional vitamin D supplementation in hypercalcaemic renal transplant recipients. Hypercalcaemia poses a potential risk for graft injury ${ }^{9}$, and may also contribute to soft-tissue and vascular calcification so normocalcaemia is a desired target in clinical practice. Existing international guidelines caution against supplementing with nutritional vitamin D in the setting of hypercalcaemia. ${ }^{10,11}$ However, we believe that because in many cases the hypercalcemia is the result of residual post-transplant hyperparathyroidism, that cautious vitamin D supplementation will avoid the deleterious effects of vitamin D deficiency while being unlikely to exacerbate the PTH driven hypercalcemia. We therefore conducted the following study to quantify the short term safety of a daily low-dose nutritional vitamin D supplement in renal transplant recipients with a recent history of serum calcium $>10 \mathrm{mg} / \mathrm{dL}$. 


\section{Methods}

This study was a two-week prospective single-arm, open-label interventional feasibility study. Ethical approval to conduct the study was obtained from the Clinical Research Ethics Committee of the Cork Teaching Hospitals and informed consent was obtained from each patient. Between October 2014 and May 2015, adult patients attending the renal transplant follow-up clinic at Cork University Hospital (CUH) who met the inclusion/exclusion criteria (Table 1) were invited to participate in the study. Inclusion criteria included a tendency towards hypercalcaemia (described as uncorrected serum calcium $>10 \mathrm{mg} / \mathrm{dL}$ ) within the 6 months prior to study commencement, combined with vitamin D insufficiency $(25(\mathrm{OH}) \mathrm{D}<30 \mathrm{ng} / \mathrm{mL})$ as per available $25(\mathrm{OH}) \mathrm{D}$ levels over the same historical period. In the hospital transplant clinic, patients are routinely reviewed every 1-3 months, therefore reviewing the results available within the previous 6 months identified those patients who had a persistent serum calcium $>10 \mathrm{mg} / \mathrm{dL}$ and not merely an individual spike in serum calcium levels. Patients with an estimated glomerular filtration rate $(\mathrm{eGFR})<30 \mathrm{ml} / \mathrm{min} / 1.73 \mathrm{~m}^{2}$ were excluded from participation. The study was conducted by the hospital renal dietitian.

At baseline, an early-morning spot urine sample was collected, and analysed for a calcium: creatinine ratio (urine calcium $(\mathrm{mg} / \mathrm{L}) /$ urine creatinine $(\mathrm{mg} / \mathrm{L})$. Blood samples were also taken at baseline for serum creatinine, eGFR, serum total calcium, ionized calcium, serum phosphate, serum $\mathrm{iPTH}$ and serum albumin, which were performed on a standard clinical chemistry analyzer. $25(\mathrm{OH}) \mathrm{D}$ was analysed using the automated chemiluminescent immunoassay method

(Architect i 1000SR System, Abbott). Separate samples were taken for 1,25 $(\mathrm{OH})_{2} \mathrm{D}$ and FGF23, 
which were centrifuged, frozen and stored at $-80^{\circ} \mathrm{C}$ until required for analysis. Samples were subsequently analysed for $1,25(\mathrm{OH})_{2} \mathrm{D}$ using the enzyme immunoassay (EIA) method (Immunodiagnostics Systems (IDS) Ltd., Boldon, Tyne and Wear, UK). Samples were also analysed for the C-terminal (180-251) amino acids of fibroblast growth factor-23 (FGF23) using the enzyme-linked immunosorbent assay (ELISA) method (Immutopics Int., San Clemente, CA, USA).

Each subject met with the hospital renal dietitian who counselled them on maintaining their usual diet for the duration of the study to limit alterations in dietary intake of vitamin D or calcium from unduly influencing serum and urine levels. Time since transplantation, history of vitamin D supplement usage, consumption of vitamin D fortified foods, exposure to sunshine and usage of sunscreen was also recorded. Weight and height were recorded and BMI calculated. Each subject was provided with a 14 day supply of cholecalciferol supplements, and asked to take one 1000 IU cholecalciferol supplement (soft gel capsule) per day for 14 days (Adult D3 ${ }^{\mathrm{TM}} 1000 \mathrm{IU}$, Shield Health). At the end of the 14 day period, each subject repeated the spot urinary collection and blood analysis. Each patient met the renal dietitian at the end of the 14 day period, who checked for compliance with the supplements / dietary intake and questioned regarding timing of the early-morning spot sample.

The central tendency, spread and distribution of variables was examined using standard tabular and graphical methods. The primary analysis was a paired comparison of change in ionized calcium and urine calcium: creatinine ratio at follow-up as compared to baseline. Analysis was conducted on SPSS v18 software (SPSS Inc., Chicago, IL, USA). 


\section{Results}

Patients attending the renal transplant follow-up clinic in Cork University Hospital over an eightweek period $(\mathrm{N}=196)$ were screened using the inclusion/exclusion criteria. 45 eligible patients were identified and of these a total of 18 patients were enrolled into the study. $72 \%$ were male $(\mathrm{N}=13)$. All were Caucasian. Our centre specific approach to renal allograft immunosuppression is been based on triple therapy using corticosteroids (with a steroid minimization policy in the last 8 years), Mycophenolate Mofetil and calcineurin inhibitors (predominantly cyclosporin before 2000 and tacrolimus thereafter).

Table 2 shows the characteristics of the study group. $28 \%$ participants were overweight with 22 $\%$ of the subjects classified as obese $\left(\mathrm{BMI}>30 \mathrm{~kg} / \mathrm{m}^{2}\right)$. This is of interest as obesity is linked with vitamin D deficiency due to storage of vitamin $\mathrm{D}$ in fat cells and consequent difficulty restoring serum levels. All of the patients were long-term renal transplant recipients ( $>1$ year since transplantation). The mean eGFR in the study group was $55.7 \mathrm{~mL} / \mathrm{min} / 1.73 \mathrm{~m}^{2}$, corresponding to stage CKD 3T. Only 1 patient reported vitamin D supplement usage within the 6 months prior to the study, and in that individual case supplementation had discontinued 3 months prior to study enrolment.

Table 3 compares the baseline and post-intervention serum and urinary parameters. All baseline albumin levels were $>4 \mathrm{~g} / \mathrm{dL}$ therefore we reported uncorrected total serum calcium in addition to ionized calcium. Following the 2-week intervention median (IQR) change in serum calcium from baseline to follow-up was -0.08 ( -3.6 to 0.08$) \mathrm{mg} / \mathrm{dL}, \mathrm{p}=0.3$. There was no substantial change in 
FGF23 (median change: $-1.9 \mathrm{RU} / \mathrm{mL}$ ). The median (IQR) change in the urinary calcium:creatinine ratio was 0.001 ( -0.026 to 0.299$) \mathrm{mg} / \mathrm{mg}, \mathrm{p}=0.88$ which was not significant. Mean (sd) baseline

urine calcium: creatinine ratio was $0.16(0.1) \mathrm{mg} / \mathrm{mg}$ which is below the threshold for hypercalciuria $(>0.2 \mathrm{mg} / \mathrm{mg})$. At baseline, PTH correlated with ionized calcium $\mathrm{r}=0.69, \mathrm{p}=0.03$. This was the only correlation of significance.

Figures 1-3 illustrate the change in median values for $25(\mathrm{OH}) \mathrm{D} ; 1,25(\mathrm{OH})_{2} \mathrm{D}$, and ionized calcium respectively pre and post intervention.

\section{Discussion}

This study shows that a 1000 IU/day cholecalciferol supplement can improve vitamin D status in vitamin $\mathrm{D}$ insufficient renal transplant recipients with a history of serum calcium $>10 \mathrm{mg} / \mathrm{dL}$ without increasing serum calcium or causing hypercalciuria over a short-term period.

Although the optimal vitamin D status in renal transplantation has yet to be defined, it has been suggested by the Endocrine Society Clinical Practice Guidelines that patients at risk of vitamin D deficiency should be screened and that vitamin D deficiency is defined as a $25(\mathrm{OH}) \mathrm{D}$ below 20 $\mathrm{ng} / \mathrm{mL}$ and insufficiency as a $25(\mathrm{OH}) \mathrm{D}$ of $21-29 \mathrm{ng} / \mathrm{mL} .{ }^{12}$ Likewise the National Kidney Foundation guidelines defined vitamin D insufficiency as a serum $25(\mathrm{OH}) \mathrm{D}<30 \mathrm{ng} / \mathrm{mL} .{ }^{10}$ Inclusion criteria for this study were vitamin D insufficiency/ deficiency combined with a recent history of a trend towards hypercalcaemia, defined in this study as a total serum calcium $>10$ $\mathrm{mg} / \mathrm{dL}$ within the previous 6 months. In total, $69 \%$ of subjects were classified as a deficient vitamin D status $(25(\mathrm{OH}) \mathrm{D}<20 \mathrm{ng} / \mathrm{mL}$ ) while $31 \%$ were insufficient $(25(\mathrm{OH}) \mathrm{D}$ of $21-30$ $\mathrm{ng} / \mathrm{mL})$. 
A previous study conducted among the same population revealed that a high percentage of these patients have an inadequate dietary intake of vitamin D. ${ }^{13}$ In fact $93 \%$ of that study's participants failed to achieve their recommended daily intake of vitamin D from diet. In addition, in the present study, only a minority (5\%) reported usage of vitamin D fortified foods. Fortified foods such as fortified milk and yogurt would frequently be recommended to renal transplant recipients as a mode of increasing their calcium and/or vitamin D intake. However these patients may not have been actively encouraged to consume these foods due to concerns regarding their calcium concentrations.

Significantly this present study found a high compliance to skin protection advice, with $94 \%$ participants reporting regular usage of sun protection factor preparations. It is known that a sunscreen with an SPF 30 reduces the skins production of vitamin D by more than $95 \%{ }^{14}$ Patients would typically use a sunscreen with a very high protection index thereby extensively compromising this important route of vitamin D production. Additionally, it has been shown that at latitudes of $42^{\circ} \mathrm{N}$ there is virtually no cutaneous vitamin $\mathrm{D}$ production during the months of November through February. Moreover, in Edmonton, Canada, which is at $52^{0} \mathrm{~N}$-the same latitude as Cork $\left(51.89^{0} \mathrm{~N}\right)$ - this period further extends from mid-October to April due to the increased zenith angle of the sun at this latitude. ${ }^{15}$ Our study was conducted between October and May which includes the winter season in Ireland. Stavroulopoulos et al ${ }^{1}$ observed that the patients who had their vitamin D status checked in the Summer had the highest levels of $25(\mathrm{OH})$ $\mathrm{D}(45 \pm 16 \mathrm{nmol} / \mathrm{L})$ in comparison with those patients who had their $25(\mathrm{OH}) \mathrm{D}$ levels checked in the Winter $(24 \pm 16 \mathrm{nmol} / \mathrm{L})$. This was a UK study with a latitude of $52^{\circ} \mathrm{N}$, practically identical to that of Cork. 
Therefore, limited sunlight exposure due to season, latitude and time of day, further exacerbated by use of sunscreen and inadequate dietary vitamin $\mathrm{D}$ intake can give rise to vitamin $\mathrm{D}$ deficiency.

A further factor contributing to altered levels of vitamin D metabolites is elevated levels of fibroblast growth factor 23 (FGF23). FGF23, a phosphaturic hormone secreted by osteocytes, is stimulated by phosphorus retention early in CKD and levels of FGF23 can remain elevated in the setting of renal transplantation. The effect of FGF23 is on its receptor Klotho which is found in both renal and parathyroid cells, and results in a decrease in the activation of $25(\mathrm{OH}) \mathrm{D}$ in the kidney, and a decrease in PTH secretion by the parathyroid glands. FGF23 also induces the activity of the inactivating enzyme 24-alpha-hydroxylase in the kidney resulting in decreased circulating levels of both $25(\mathrm{OH}) \mathrm{D}$ (which it converts to $24,25(\mathrm{OH})_{2} \mathrm{D}$ ) and $1,25(\mathrm{OH})_{2} \mathrm{D}$ (which it converts to $1,24,25(\mathrm{OH})_{3}$ vitamin $\mathrm{D}$ ). $72 \%$ of the subjects in the present study had an elevated baseline FGF23 (>100 RU/mL). Wolf et al ${ }^{16}$ carried out the first study investigating the effect of increased FGF23 on mortality and allograft survival in 984 long-term renal transplant patients, with a median transplant vintage of 72 months, and found that elevated FGF23 levels were independently associated with increased mortality and graft loss. The median (IQR) FGF23 level at enrolment in that prospective study was 28 (20 to 43$) \mathrm{RU} / \mathrm{mL}$ which is much lower than our results which describe a median (IQR) FGF23 of 150 (98-178) RU/mL.

Additionally, immunosuppressants are also known to effect vitamin D metabolism, e.g. glucocorticoids directly increase $25(\mathrm{OH}) \mathrm{D}$ and $1,25(\mathrm{OH})_{2}$ D catabolism, and also indirectly via increasing FGF23 levels which impacts on $25(\mathrm{OH}) \mathrm{D}$ and 1,25 $(\mathrm{OH})_{2} \mathrm{D}$ levels as previously discussed. ${ }^{17}$ Animal studies have shown that cyclosporin and tacrolimus (calcineurin inhibitors) suppress the Vitamin D Receptor. ${ }^{18}$ 
Current guidelines for management of vitamin D status in the setting of renal transplantation are non-specific or rely on guidelines for non-transplanted CKD patients of the same renal function. The 2017 KDIGO CKD-MBD guideline update continues the 2009 recommendation to measure $25(\mathrm{OH})$ D levels, and in those patients with deficiency and insufficiency, treatment strategies recommended for the general population be implemented. ${ }^{19}$ Courebaisse et al ${ }^{20}$ proposed a supplementation regimen based on their research, which compared the effect of cholecalciferol supplementation in normocalcaemic vitamin D deficient renal transplant recipients versus a nonsupplemented control group and concluded that in the treatment group, 100,000 IU cholecalciferol every 2 weeks successfully and safely replete $25(\mathrm{OH})$ D status. However, when the cholecalciferol dose was decreased to 100,000 IU every other month in the maintenance phase of the treated group, by month 12 , serum $25(\mathrm{OH})$ D concentrations decreased significantly and only remained above $30 \mathrm{ng} / \mathrm{mL}$ in $51 \%$ of patients. The investigators concluded that Holick's recommendation for a maintenance dose of 100,000 IU cholecalciferol per month in patients with CKD is valid in the renal transplant group also. In the present study following only 14 days of supplementation with a low dose of cholecalciferol (1000 IU/day), $25(\mathrm{OH}) \mathrm{D}$ levels increased significantly from a mean of $15.9 \mathrm{ng} / \mathrm{mL}$ to $20.8 \mathrm{ng} / \mathrm{mL}(\mathrm{p}<0.001)$ demonstrating the effectiveness of this level of supplementation.

The incidence of hypercalcaemia amongst renal transplant populations varies amongst studies. Prevalence rates will vary between studies due to differences in definitions of hypercalcaemia and whether ionized, total serum or corrected serum calcium is used. Stavroulopoulos et $\mathrm{al}^{1}$ found that $25 \%$ of the long-term transplant subjects in that study were hypercalcaemic, (defined as albumin-corrected calcium $>10.4 \mathrm{mg} / \mathrm{dL}$ ), similarly our previous research demonstrated a prevalence of $24 \%$ (defined as albumin-corrected serum calcium $>10.5 \mathrm{mg} / \mathrm{dL}$ ). ${ }^{13}$ When calcium 
is measured as ionized calcium, higher levels are prevalent especially in the first year. ${ }^{21}$ In a prospective, observational study of 201 successfully transplanted patients, results indicated skeletal loss of calcium, mediated by high PTH levels is the most likely cause of posttransplantation hypercalcaemia. ${ }^{22}$ Hyperparathyroidism was present in our study with a mean (sd) baseline PTH of 1202 (678) pg/mL. Baseline PTH correlated with baseline ionized calcium, $\mathrm{r}=0.69, \mathrm{p}=0.03$ which supports the hyperparathyroidism-mediated hypercalcaemia mechanism. Ionized calcium decreased significantly following the intervention. This was an unexpected finding. It could be hypothesised that as a result of vitamin D supplementation, bone activity increased resulting in increased uptake of calcium by the bone. There was also a decrease in mean PTH at the end of the intervention although this was not significant.

Despite the low levels of $25(\mathrm{OH}) \mathrm{D}$, baseline $1,25(\mathrm{OH})_{2} \mathrm{D}$ levels were in the reference range (mean $41.8 \mathrm{pg} / \mathrm{mL}$ ). This finding is in agreement with Lomonte et $\mathrm{al}^{23}$ who reported that the calcitriol levels in a selected cohort of renal transplant patients were normal and also reported no correlation between $25(\mathrm{OH}) \mathrm{D}$ status and $1,25(\mathrm{OH})_{2}$ D concentrations. Conversely a previous study showed that female gender, good renal function, high $25(\mathrm{OH}) \mathrm{D}$ and high PTH levels were all independently associated with high calcitriol levels, although that study looked at the early post-transplant period. ${ }^{22}$ Mazzaferro et al ${ }^{24}$ noted a lower impact of $25(\mathrm{OH}) \mathrm{D}$ insufficiency on $1,25(\mathrm{OH})_{2} \mathrm{D}$ levels in transplant recipients compared with CKD patients and also reported a positive relationship between calcium and $1,25(\mathrm{OH})_{2}$ D levels in a group of 136 renal transplant patients. They speculated that extra-renal hydroxylases contribute to the pool of serum 1,25 $(\mathrm{OH})_{2} \mathrm{D}$ since renal production of calcitriol decreases in the setting of higher serum calcium levels. In the present study, mean $1,25(\mathrm{OH})_{2} \mathrm{D}$ levels increased significantly with cholecalciferol supplementation. This suggests that lower daily doses of cholecalciferol 
supplementation may be more appropriate in this group versus mega-doses. It would be of interest to compare the effect of low versus high dose cholecalciferol supplementation on 1,25 $(\mathrm{OH})_{2}$ vitamin D and also on the concentrations of $24,25(\mathrm{OH})_{2}$ vitamin $\mathrm{D}$ in this group.

Our group profile was homogenous, with a majority of middle-aged men. It is known that women tend to have lower levels of $25(\mathrm{OH}) \mathrm{D}$ compared with men. ${ }^{25}$ Although our group consisted entirely of Caucasians which would comprise the predominant ethnicity in the local population it is important to note that ethnic groups with dark skin-colour are more at risk of vitamin D deficiency as melanin is an effective natural sunscreen. ${ }^{4}$ Vitamin D status is also affected by aging as levels of 7-dehydrocholesterol decline with age, so there is less substrate for cutaneous vitamin D production. ${ }^{4}$

Limitations of the study include the small number of subjects and the short duration of the intervention. Despite this we see relatively uniform effects with some significant results being evident even in this small sample size. While the intervention period was not long enough to achieve adequate $25(\mathrm{OH})$ D levels in all participants (dependent on their baseline $25(\mathrm{OH}) \mathrm{D}$ levels), this initial safety study supports the feasibility and safety of conducting, with appropriate monitoring, a longer term interventional trial to quantify the risks and benefits of vitamin D supplementation in this population, particularly in relation to calcium metabolism. Such a trial is required as the long term safety and benefit of vitamin D supplementation in transplant patients with hypercalcaemia cannot be inferred from the current work yet it represents a potentially important and inexpensive intervention that may improve the bone and general health of such subjects.

The patients that participated in this study discontinued the vitamin D supplementation after the 
14-day trial, as this research needs to be extended before a general supplementation regimen can be implemented in this subgroup. However, patients who required additional repletion would have been individualised to a supplementation regimen and monitored closely by the renal dietitian and medical team. As a result of the study, a greater awareness of the prevalence of 25 $(\mathrm{OH})$ vitamin D inadequacy in this population has lead to routine monitoring of $25(\mathrm{OH}) \mathrm{D}$ levels amongst our transplant patients and appropriate correction of same using a variety of nutritional vitamin D supplements.

\section{Practical Application}

Cautious daily dosing of cholecalciferol appears to safely restore $25(\mathrm{OH})$ D concentrations in renal transplant patients at risk of hypercalcaemia in the short term. Further research is needed to establish long term safety in this sub-group. 


\section{References}

1.Stavroulopoulos A, Cassidy MJD, Porter CJ, Hosking DJ, Roe SD. Vitamin D status in renal transplant recipients. Am J Transplant. 2007; 7: 2546-2552.

2.Querings K, Girndt M, Geisel J, Georg T, Tilgen W, Reichrath J. 25-Hydroxyvitamin D deficiency in renal transplant recipients. J Clin Endocrinol Metab. 2006; 91: 526-529.

3.McGregor R, Li G, Penny H, Lombardi G, Afzali B, Goldsmith DJ. Vitamin D in renal Transplantation- From biological mechanisms to clinical benefits. Am J Transplant. 2014; 14 : 1259-1270.

4. Holick M. Sunlight and vitamin D for bone health and prevention of autoimmune diseases, cancers and cardiovascular disease. Am J Clin Nutr. 2004; 80: 1678S-88S.

5. Jones G. Extrarenal vitamin D activation and interactions between vitamin D2, vitamin D3 and vitamin D analogs. Annu Rev Nutr. 2013; 33: 23-44.

6. Armas L and Heaney R. Vitamin D: The iceberg nutrient. J Ren Nutr. 2011; 21 (2):134-139.

7. Keyzer C, Riphagen I, Joosten M, et al. Associations of $25(\mathrm{OH})$ and $1,25(\mathrm{OH})_{2}$ Vitamin D with long-term outcomes in stable renal transplant recipients. J Clin Endocrinol Metab. 2015; $100(1): 81-89$.

8. Filipov J, Zlatkov B, Dimitrov E, Svinarov D. Higher 25-hydroxyvitamin D levels are associated with lower proteinuria in kidney transplant recipients. Exp Clin Transplant. 2016; 14 : $629-633$.

9. Zofkova I. Hypercalcaemia. Pathophysiological aspects. Physiol Res. 2016; 65: 1-10. 
10. National Kidney Foundation. K/DOQI clinical practice guidelines for bone metabolism and disease in chronic kidney disease. Am J Kidney Dis. 2003; 42: S1-S201

11. European Best Practice Guidelines Expert group in Renal Transplantation: European best practice guidelines for renal transplantation. Section IV.8: long-term management of the transplant recipient. Bone disease. Nephrol Dial Transplant. 2002; 17 (4): 43-48. 10.

12. Holick M, Binkley N, Bischoff-Ferrari H, et al. Evaluation, Treatment, and Prevention of vitamin D deficiency: an Endocrine Society Clinical Practice Guideline. J Clin Endocrinol Metab. 2011; 96 (7): 1911-1930.

13. Lynch I, Eustace J, Plant W, et al. Inadequate Dietary Calcium and Vitamin D Intakes in renal-transplant recipients in Ireland. J Ren Nutr. 2007; 17 (6): 408-415.

14. Nair R and Maseeh A. Vitamin D: The "sunshine" vitamin. J Pharmacology and Pharmacotherapeutics. 2012; 3 (2): 118-126.

15. Webb A R, Kline 1, Holick M. F. Influence of season and latitude on the cutaneous synthesis of vitamin D3: Exposure to winter sunlight in Boston and Edmonton will not promote vitamin D3 synthesis in human skin. J Clin Endocrinol Metab. 1988; 67, (3), 373-378.

16. Wolf M, Molnar M Z, Amaral A P, et al. Elevated fibroblast growth factor 23 is a risk factor for kidney transplant loss and mortality. Journal of American Society of Nephrology. 2011; 22: 956-966.

17. Cianciolo G, Galassi A, Capelli I, Angelini ML, La Manna G, Cozzolino M. Vitamin D in Kidney Transplant Recipients: Mechanisms and therapy. Am J Neph. 2016; 43: 397-407. 
18. Lee CT, Ng HY, Lien YH et al. Effects of cyclosporine, tacrolimus and rapamycin on renal calcium transport and vitamin D metabolism. Am J Nephrol. 2011; 34 (1): 87-94 doi: $10.1159 / 000328874$.

19. Ketteler M, Block G, Evenpoel P, at al. Executive summary of the 2017 KDIGO Chronic Kidney Disease- Mineral and Bone Disorder (CKD-MBD) Guidelines Update: what's changed and why it matters. Kidney Int. 2017; 92: 26-36.

20. Courebaisse M, Thervet E, Souberbielle JC, et al. Effects of vitamin D supplementation on the calcium-phosphate balance in renal transplant patients. Kidney Int. 2009; 75: 646-651.

21. Messa P, Cafforio C, Alfieri C. Clinical Impact of hypercalcaemia in kidney transplant. Int J Nephrol. 2011; 906832.

22. Evenpoel P, Van Den Bergh B, Naesens M, et al. Calcium metabolism in the early posttransplantation period. Clin J Am Soc Nephrol. 2009; 4: 665-672.

23. Lomonte C, Antonelli M, Vernaglione L. Are low plasma levels of $25(\mathrm{OH})$ vitamin D a major risk factor for hyperparathyroidism independent of calcitriol in renal transplant patients? $J$ Nephrol. 2005; 18: 96-101.

24. Mazzaferro S, Pasquali M, Pugliese F, et al. Distinct impact of vitamin D insufficiency on calcitriol levels in chronic renal failure and renal transplant patients: a role for FGF23? $J$ Nephrol. 2012; 25(06): 1108-1118.

25. Messa P, Regalia A, Alfieri C M. Nutritional vitamin D in renal transplant patients: Speculations and reality. Nutrients. 2017: 9, 550; doi: 10.3390/nu9060550. 
Table 1. Inclusion and exclusion criteria

$\begin{array}{ll}\text { Inclusion } & \text { - Serum calcium }>10 \mathrm{mg} / \mathrm{dL} \\ & \bullet \\ & 25(\mathrm{OH}) \mathrm{D}<30 \mathrm{ng} / \mathrm{mL} \\ \bullet & >16 \text { years of age }\end{array}$

Exclusion $\quad$ eGFR $<<30 \mathrm{ng} / \mathrm{mL}$

- Nutritional vitamin D supplementation within 3 months prior to study commencement.

- Acute illness e.g. metastatic bone disease, sarcoidosis

- Inability to comply with protocol 
Table 2. Characteristics of study participants

Parameter

Value

Age (yr), mean (SD)

$53(13)$

Male gender, n (\%)

$13(72)$

eGFR (mL/min/1.73m²), mean (SD)

$55.7(11.9)$

BMI $\left(\mathrm{Kg} / \mathrm{m}^{2}\right)$, mean (SD)

$26.5(4.9)$

Diabetes mellitus, n (\%)

$4(22)$

Reported usage of fortified foods, n (\%)

Reported regular usage SPF, n (\%)

$17(94)$

Time since transplant (yr), mean (SD)

$7.6(4.8)$

Reported use of vitamin D supplements, n (\%)

$1(5)$

eGFR: estimated glomerular filtration rate; BMI: body mass index; SPF: sun protection factor 
Table 3. Baseline and post-intervention serum and urinary parameters

\begin{tabular}{|c|c|c|c|}
\hline Parameter & Baseline mean (sd) & Final mean (sd) & $\mathbf{p}$ \\
\hline $25(\mathrm{OH})$ vitamin $\mathrm{D}(\mathrm{ng} / \mathrm{mL})[\mathrm{n}=16]$ & $15.9(5.97)$ & $20.8(4.9)$ & $<0.001$ \\
\hline $1,25(\mathrm{OH})_{2}$ vitamin $\mathrm{D}(\mathrm{pg} / \mathrm{mL})[\mathrm{n}=15]$ & $41.8(26.6)$ & $49.4(29.1)$ & 0.05 \\
\hline Calcium (mg/dL) & $10.5(0.6)$ & $10.4(0.5)$ & 0.33 \\
\hline Ionised calcium (mg/dL) [n=18] & $5.2(0.3)$ & $5.16(0.3)$ & 0.05 \\
\hline Phosphate (mg/dL) & $2.6(0.3)$ & $2.7(0.5)$ & 0.08 \\
\hline PTH (pg/mL) & $1201.7(677.7)$ & $1126.3(544.8)$ & 0.74 \\
\hline FGF23 (RU/mL) & $143.2(45.0)$ & $141.6(40.3)$ & 0.90 \\
\hline Urine Calcium:Creatinine ratio (mg/mg) & $0.16(0.1)$ & $0.15(0.10)$ & 0.88 \\
\hline Albumin $(\mathrm{g} / \mathrm{dL})$ & $4.4(0.28)$ & $4.34(0.24)$ & 0.24 \\
\hline
\end{tabular}


Figure 1. Median serum $25(\mathrm{OH}) \mathrm{D}$ pre and post intervention

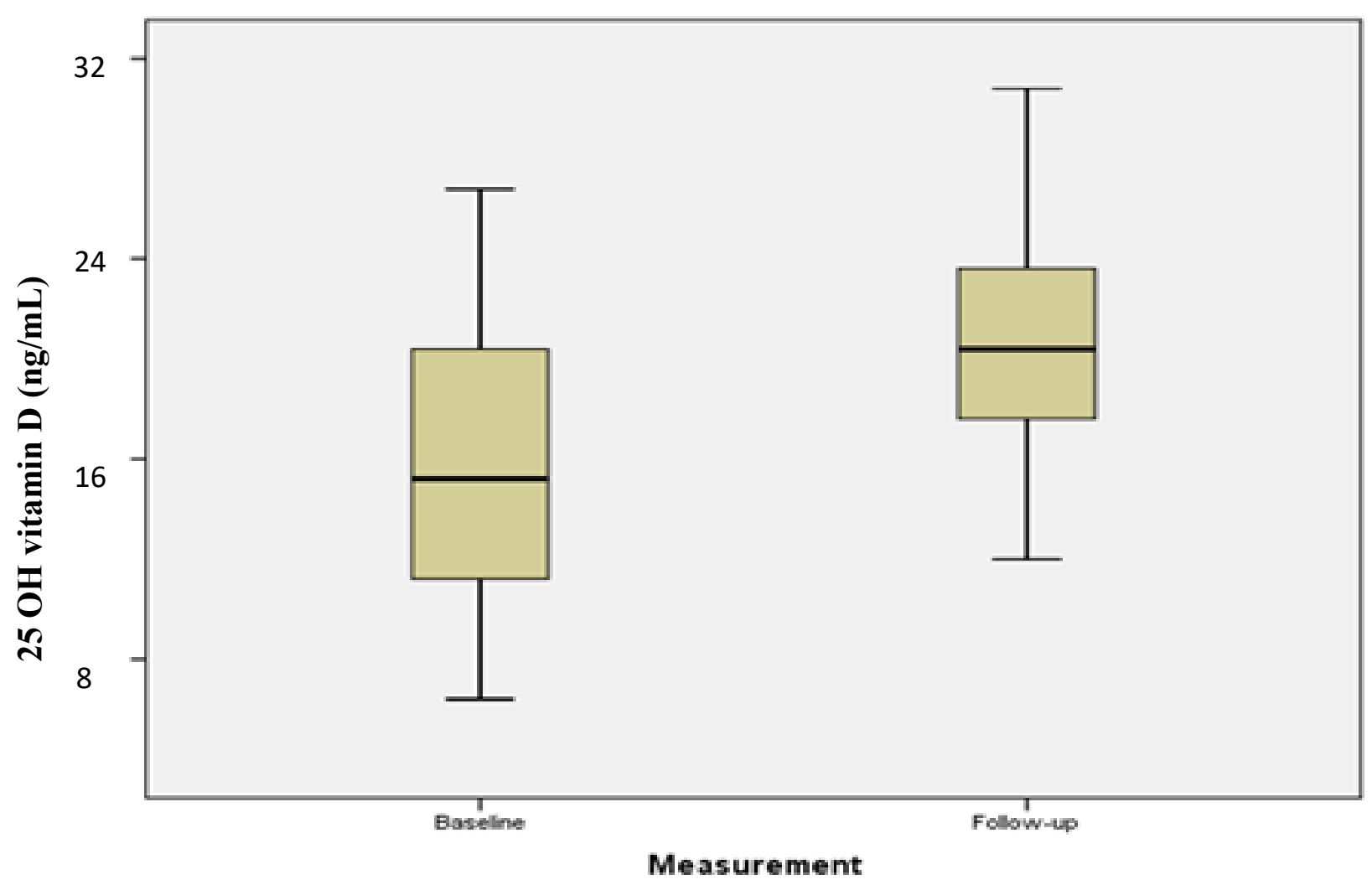


Figure 2. Median serum 1,25 $(\mathrm{OH})_{2} \mathrm{D}$ pre and post intervention

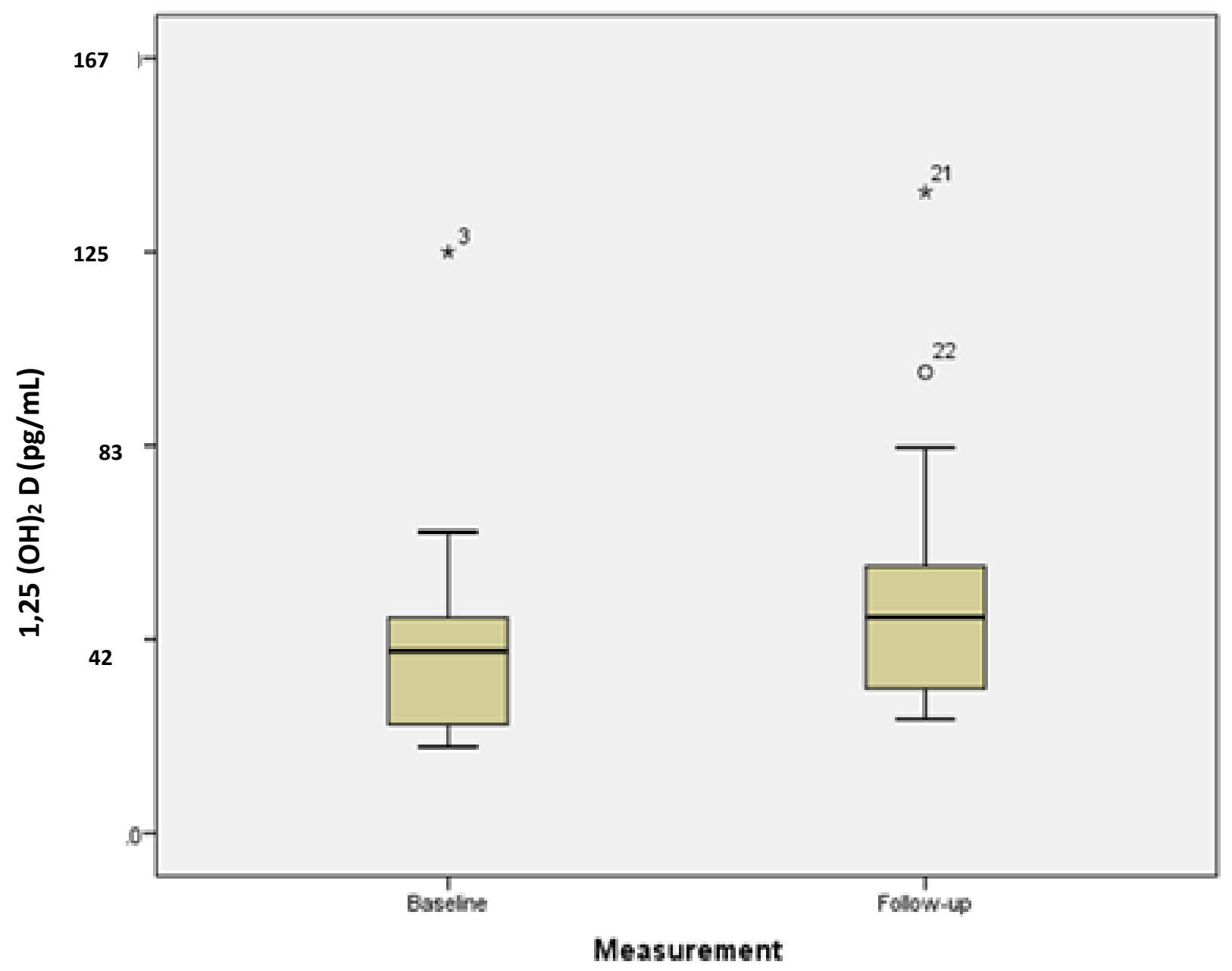


Figure 3. Median serum ionized calcium pre and post intervention.

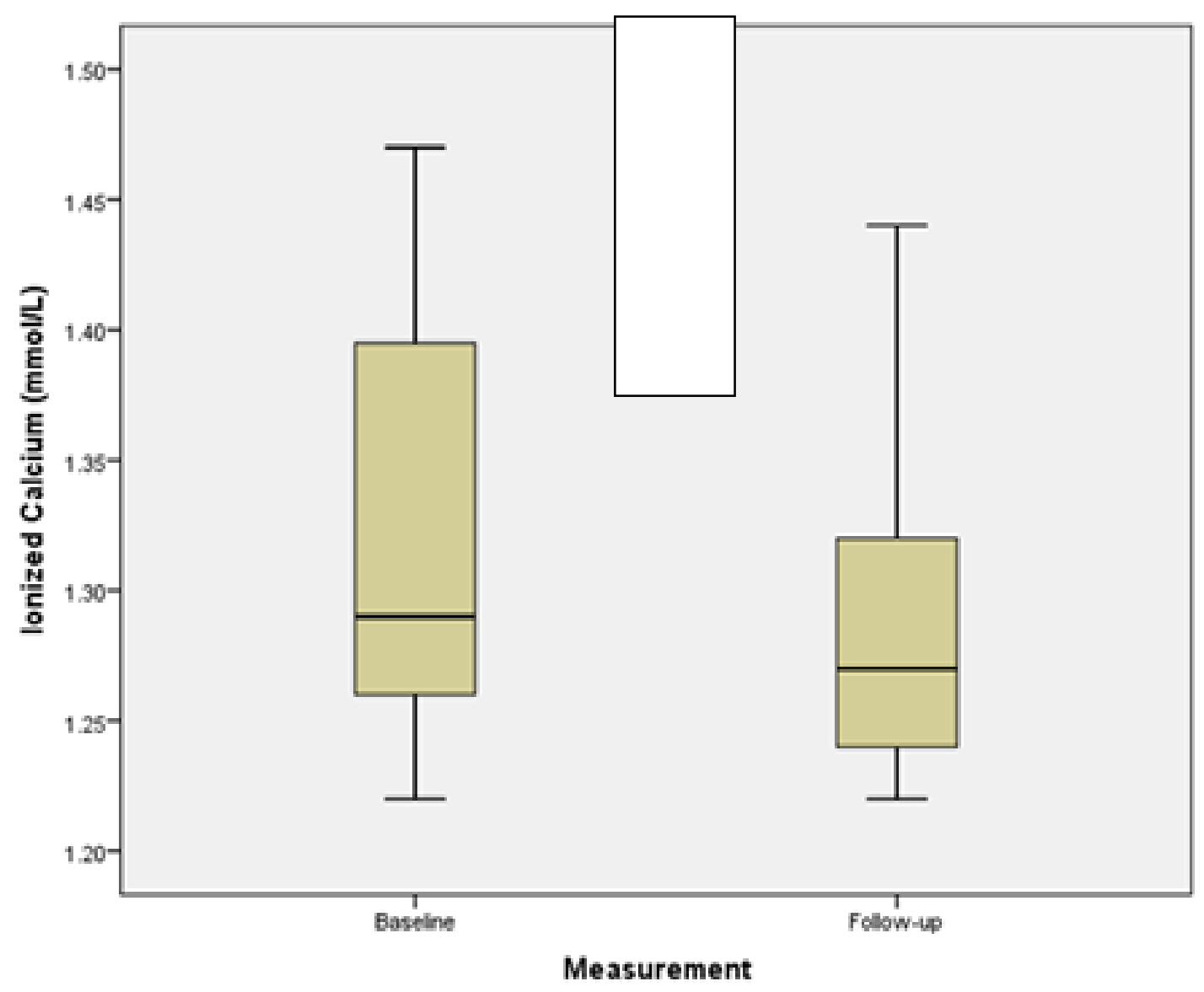


